\title{
The state of art in the horticulture lighting
}

\author{
Marian Gilewski* \\ Faculty of Electrical Engineering, Bialystok University of Technology, Wiejska 45A, 15-351 Bialystok
}

Received November 21, 2020; accepted November 25, 2020; published December 17, 2020

\begin{abstract}
The article presents an overview of currently used greenhouse lighting systems. It does not apply to traditional sodium lighting systems, but only to the most modern LEDs. The publication presents descriptions of lamp designs, both foreign and Polish. The aim of the work is not only to review solutions, but also to identify the reasons for the low transfer of scientific and technical solutions to business. There are several barriers to overcome, mainly subjective ones, so that new solutions can be implemented and developed.
\end{abstract}

Nowadays, LED lamps are widely used as a light source to stimulate greenhouse crops [1]. The spectrum of radiation, its power and photoperiod are the most important parameters of greenhouse lighting. Climate change has indicated two paths for the development of greenhouse lighting: closed systems and replenishing systems. The first system is used in sealed vegetable farms in the polar and equatorial areas. Replenishing systems complement the insufficient natural radiation in the greenhouse, currently mainly with LED lamps. This category of systems is dominant in the temperate zone, including Poland.

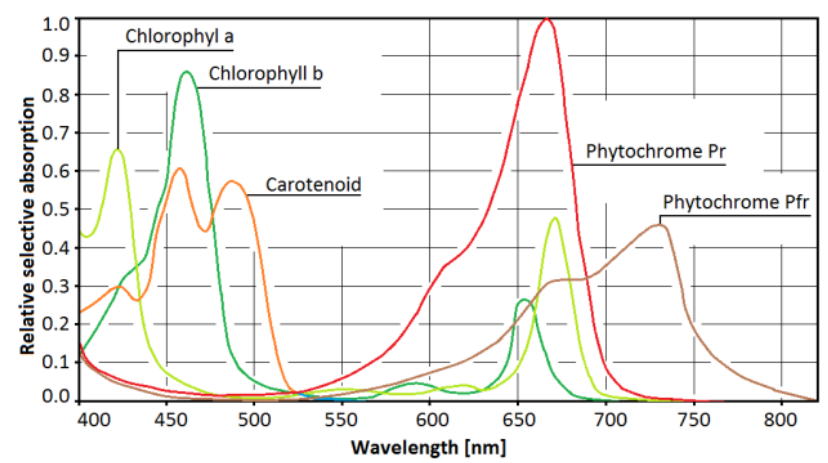

Fig. 1. Absorption spectra of plant species [2].

The influence of optical radiation on plant growth has been recognized and tested (Fig. 1) [2-5]. Thus, the availability of knowledge is not a problem, but its translation into specific technical solutions. Research carried out shows that the optimal share of radiation power is as follows: UV - 5\%, VIS blue/green - 20\%, VIS $\mathrm{red} / \mathrm{deep}$ red $-70 \%$ and VIS far red about $5 \%$. However, even excellent scientific solutions in this field are severely verified by the user market. Its determinants are: business profitability, reliability and proven design. It is understandable, because modern greenhouse factories of vegetables, fruit and flowers cover several hectares. Therefore, these are very expensive systems, hence ensuring the reliability and uniformity of lighting is a primary problem. The most common are top lighting systems (Fig. 2), in which plant canopies are illuminated from the ceiling, and the height of lamp mounting changes with the growth of the crop.

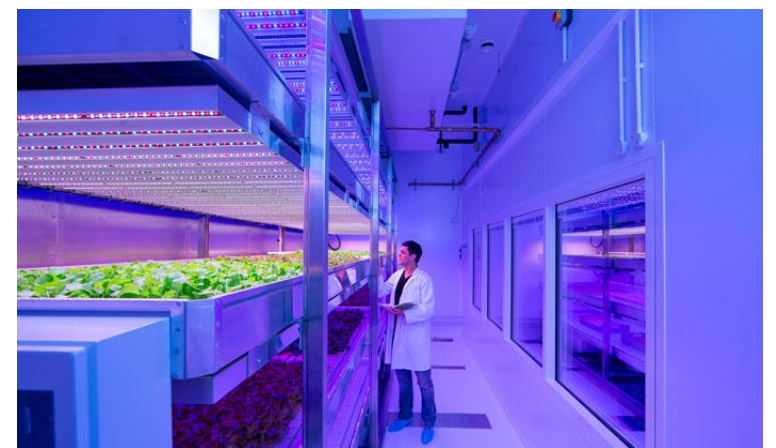

Fig. 2. Top lighting in city farming - plants ripen without daylight [6]

Natural lighting is supplemented in replenishing systems, and for this purpose, top lighting is sometimes combined with interlighting (intercanopy lighting, Fig. 3). Despite practical applications, the literature does not overestimate the importance of interlighting. It has been shown that the radiation applied to the upper and lower leaf surfaces is absorbed with different efficiency. An adequate spectrum of optical radiation is very important for the growth of the biomass of the crop and the content of active substances in the plant. Therefore, its effect is comparable to the size of the active surface area of the leaves. Despite this, some lamp users do not appreciate this fact.

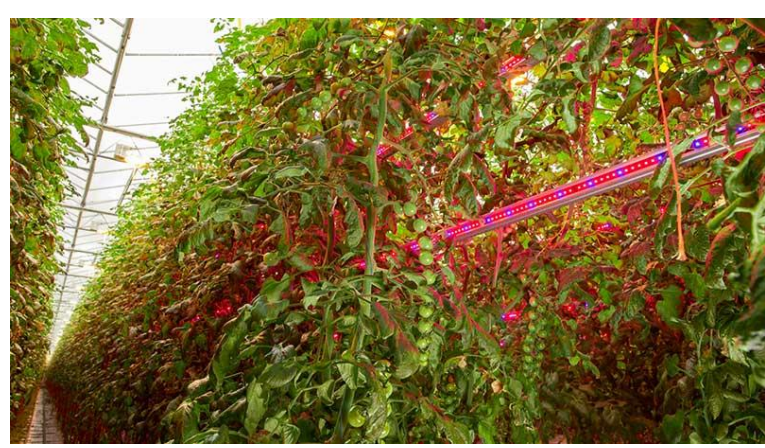

Fig. 3. Sample suspension of interlighting lamps [7]. 
There are commercial LED lamps, which are dedicated as replacements for sodium lamps (HPS) and ceramic metal halide $(\mathrm{CMH})$ lamps. These lamps provide white LED light and their only advantage is higher energy efficiency than that of HPS or CMH lamps. (Fig. 4). They do not provide the radiation spectrum required by plants, the only tunable element is the dimmable power supply.

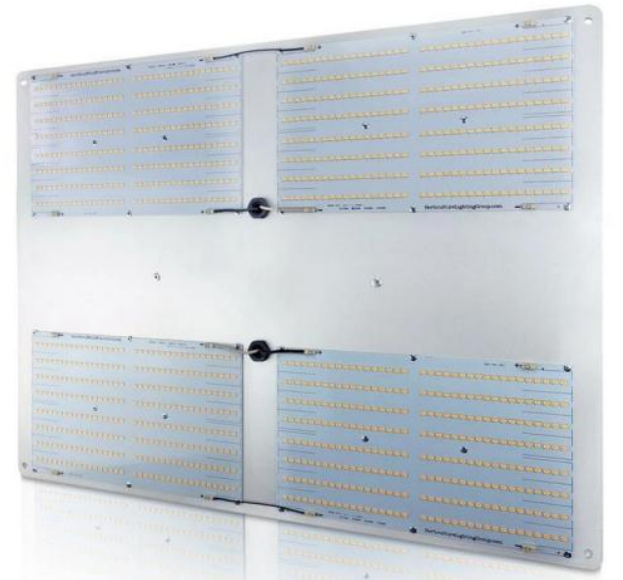

Fig. 4. Indoor Horticulture LED grow light HLG550 [8].

Their photonic efficiency is about $2.5 \mu \mathrm{mol} / \mathrm{J}$, light efficiency $170 \mathrm{~lm} / \mathrm{W}$, photosynthetic flux PPF of 1200 $\mu \mathrm{mol} / \mathrm{s}$ for $500 \mathrm{~W}$ electrical power.

The Neonica Growy LED series is an example of a more technologically advanced solution for greenhouse lamps (Fig. 5). It is a very popular design solution for lamps that are commonly used in greenhouse systems. Its advantage is a universal modular solution that uses only a few types (Fig. 6) of LED sources [10].

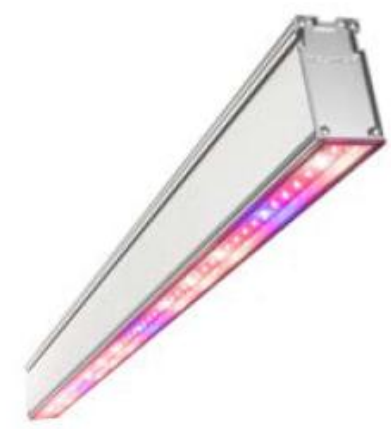

Fig. 5. Neonica Growy LED Plus 318 [9].

Despite the relatively similar value of the photosynthetic flux, this type of lamp provides a radiation spectrum that is more effectively suited to the needs of the crop [11]. The main advantages of the discussed solution are high reliability and low sensitivity to interference. The construction consists of only a few types of optical emitters, it does not contain a complicated and complex electronic system. Moreover, the lamps can be combined into larger units that can be powered by a three-phase $\mathrm{AC}$ source.

http://www.photonics.pl/PLP

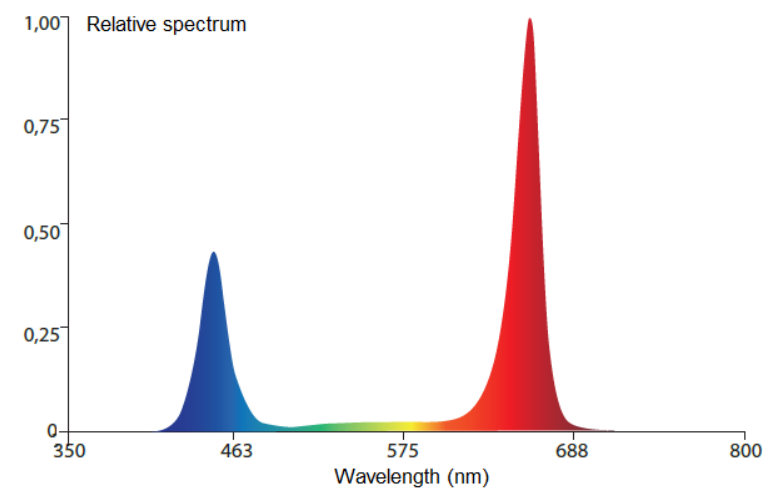

Fig. 6. Spectral distribution of the Neonica lamp [9].

A very technologically advanced solution is the DYNA type construction. Its purpose is to conduct scientific research, so the price of the lamp is relatively high, and its design solution is very complex (Fig. 7) [12].

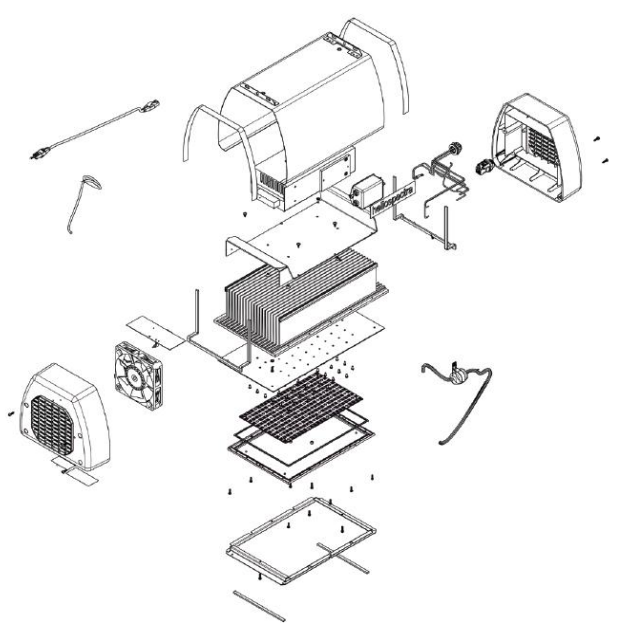

Fig. 7. Complex diagram of the DYNA lamp [12].

A rich set of LED emitters with wavelengths: $380 \mathrm{~nm}, 400$ $\mathrm{nm}, 420 \mathrm{~nm}, 450 \mathrm{~nm}, 520 \mathrm{~nm}, 630 \mathrm{~nm}, 660 \mathrm{~nm}, 735 \mathrm{~nm}$ and white $5700 \mathrm{~K}$ - enables the synthesis of very complex emission characteristics (Fig. 8). Unfortunately, the synthesis of a complex spectrum leads to a low photonic efficiency of $1.0 \mu \mathrm{mol} / \mathrm{J}$ and a photosynthetic flux PPF around $390 \mu \mathrm{mol} / \mathrm{s}$ at $400 \mathrm{~W}$ power supply. It is one of the few solutions that uses an active cooling system and temperature stabilization.

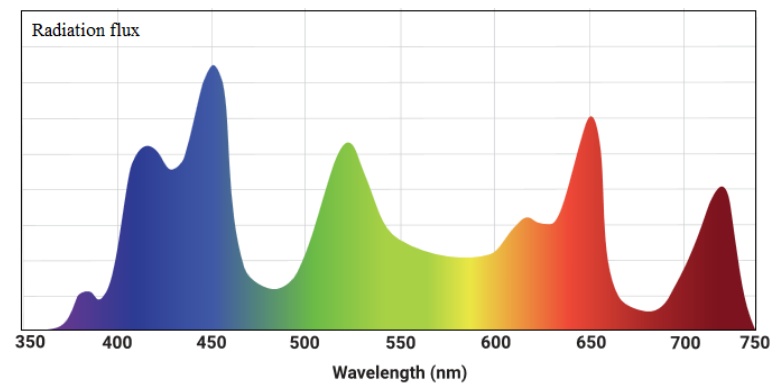

Fig. 8. Exemplary DYNA lamp output spectrum [12].

(C) 2020 Photonics Society of Poland 
Summarizing the review of LED greenhouse lamps, it should be noted that technological progress is being made not only in the construction of lamps but also in LED sources. An interesting concept in this regard is the spectral segmentation of COB LEDs (Fig. 9). In these solutions, the LED structure includes an appropriate division of the emission bands, e.g., far red $10 \%$, red $38 \%$, green $38 \%$ and blue $14 \%$.

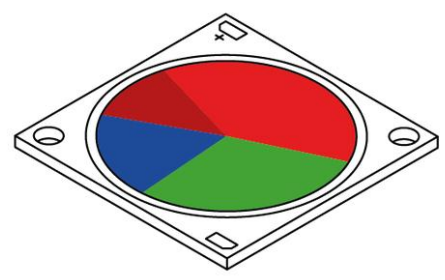

Fig. 9. Greenhouse COB LED Plantlux Full Spectrum [13].

The author, while preparing the project an adaptive greenhouse lighting system (Fig. 10) [14], encountered several technical and personal barriers. In the beginning, the relationships with the lamp manufacturers and their target users - gardeners - were the most troublesome. The motivations of producers and gardeners were different from the imaginations of the researcher. Understanding these environments, accepting some of their habits and explaining them for a long time - were the key to further cooperation. Manufacturers of LED greenhouse lamps avoid structures containing rotating elements. For them, the tightness of the housing is the most important, it is not only about the influence of moisture but also the penetration of pollinating insects.

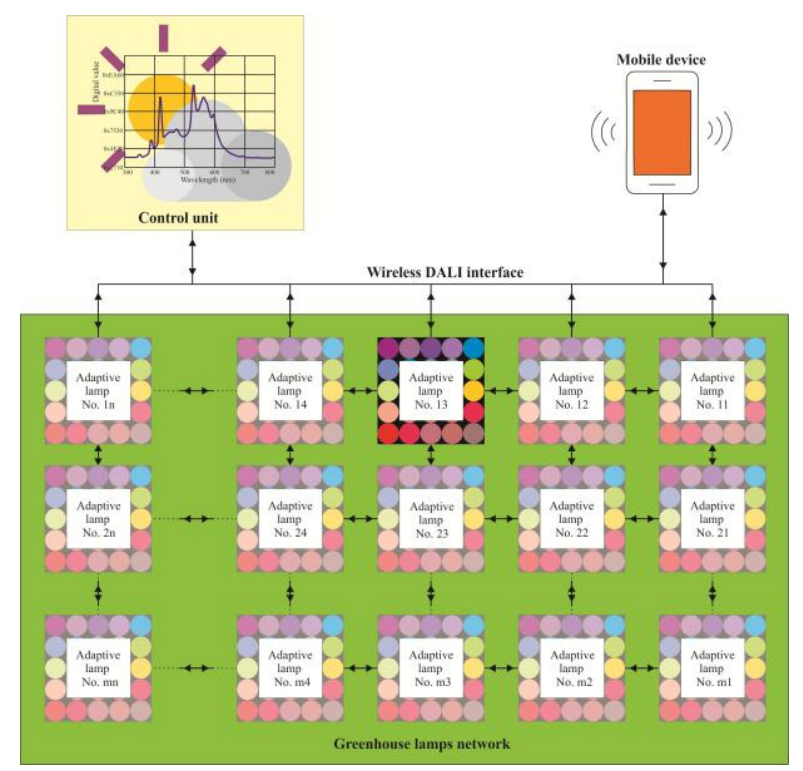

Fig. 10. The scheme of the adaptive greenhouse lighting system [14]

The design should be as simple and reliable as possible.

Gardeners tend to have a business approach and often a distrustful traditional attitude. It is very difficult for an unknown researcher to start cooperation with horticultural http://www.photonics.pl/PLP farms. Gardeners are not interested in individual pieces of new lamps, they expect verified solutions in crops with an area of single hectares.

In the initial phase, the question is often asked about the amount of profit from the use of new lighting. The scientist at this stage is not prepared and cannot provide a binding answer. Only the research of a new solution in real conditions gives an approximate answer. A direct helpful indicator is the lower energy consumption of new solutions. It sometimes happens that resistance to applying new solutions results from stereotypes or a lack of lighting knowledge. For example, there are allegations of the following type:

- LED lamps generate less heat than HPS, which makes the greenhouse cooler;

- LED lamps illuminate the greenhouse less than HPS.

In such situations it remains easy to explain that the lamps should not change the temperature of the greenhouse and their purpose is not to produce visible light, but radiation specific to plants.

Regardless of the arguments of either side, the scientist has to convince the gardener to invest his money in a new idea. The best technical solution, if it is not implemented within 5 years, can become a museum object.

\section{References}

[1] S. Ki-Ho, J. Yu-Min, O. Myung-Min, Springer 57(6), 561 (2016).

[2] M. Gilewski, Phot. Lett. Poland 11, 4 (2019).

[3] K.J. McCree, Agricultural Meteorology (Elsevier Publishing Company 1972).

[4] G. Trouwborst, J. Oosterkamp, S. Hogewoning, V. Ieperen, the 6th Int. Symposium on Light in Horticulture. Tsukuba. Japan, Nov. 2009.

[5] K. Jaworski, A. Szmidt-Jaworska, J. Kopcewicz, Springerlink.com, Journal: 10725, Article: 9609, 2011.

[6] Philips Lighting, Horticultural LED lighting applications, 2020: https://www.lighting.philips.com/main/products/horticulture.

[7] E. de Beer, P.H. van Baar, 3 reasons why intercanopy lighting is effective for high-wire vegetables, 2020: www.lighting.philips.com

[8] HLG, Refurbished HLG 550, 2020, https://horticulturelightinggroup.com/collections/lamps/products/refurbished-hlg-550-v1

[9] Neonica Polska, 2020, www.growy.eu

[10] I. Fryc, T. Dimitrova-Grekow, 6th IEEE Lighting Conference of the Visegrad Countries : LUMEN V4, Sept. 2016.

[11] EconoLux Ind. Ltd., "What Light do Plants Need", Hong Kong, 2016, http://econoluxindustries.com/light-plants-need.html.

[12] Heliospectra AB, heliospectra DYNA, 2020, https://www.heliospectra.com/led-grow-lights/dyna.

[13] Plantlux, Horticulture LED SMD lamp Plantalux XX640W, 2020, https://plantalux.pl/en/plantalux-xx640w-en/.

[14] M. Gilewski, 978-1-5386-7924-1/18/\$31.00 C2018 IEEE, 2018. 